\title{
SÓCRATES SOFISTA, BRÁS CUBAS FILÓSOFO?
}

\author{
Alex Lara Martins* \\ Universidade Federal de Minas Gerais
}

\begin{abstract}
RES U M O
Nosso objetivo é comparar as estratégias argumentativas de Sócrates e Brás Cubas, tais como ironia e aporia. Consideramos a estrutura ficcional machadiana como condição para a expressão cética, que ao desconfiar da realidade ou do que dela se supõe saber, instaura uma nova perspectiva, ou seja, outro nível de realidade que prescinde dos valores dogmáticos como Verdade e Essência. A justificativa geral para esse tipo de abordagem é que as questões ali descritas são encorpadas por situações ficcionais, gerando um ceticismo que se expressa numa obra de ficção. Brás Cubas e Sócrates esboçam conjecturas que descrevem as relações paradoxais do ser humano.
\end{abstract}

PALAVRAS - CHAVE

Machado de Assis, Sócrates, Ceticismo

Nossa hipótese inicial é que Machado esboça conjecturas que descrevem as relações paradoxais do homem, valorizando mais o exame do problema que sua resolução, de modo a manter seus interlocutores em aporia. A estrutura ficcional é condição para a expressão de um tipo de ceticismo, já que as questões filosóficas são dramatizadas e este ceticismo se expressa numa obra de ficção. Por ter uma posição original frente à disputa cética, julgamos apropriado tratar Machado de Assis dentro do escopo de uma História da Filosofia, inclusive da história do pensamento nacional.

No presente estudo, focalizamos as semelhanças entre as estratégias argumentativas de Sócrates e Machado de Assis, em especial os primeiros diálogos platônicos ${ }^{1}$ e as Memórias Póstumas de Brás Cubas. Nenhum deles escreveu Filosofia. Temos descrições de como Sócrates viveu, sabemos aproximadamente o que pensava, como debatia, quem eram seus pares etc., embora seja consensual considerá-lo filósofo. De Machado temos poucos estudos consistentes que o relacionam à filosofia, embora seja unânime considerá-lo cético. ${ }^{2}$

\footnotetext{
*alexlm@bol.com.br

${ }^{1}$ Refiro-me ao Sócrates "elêntico", cujos diálogos são (em ordem alfabética): Apologia, Cármides, Críton, Eutífron, Górgias, Hippias Menor, Ín, Laques, Protágoras e República I, embora encontremos resquícios desse tipo de argumentação noutros diálogos. Sobre a divisão dos diálogos, ver VLASTOS. Socrates: Ironist and Moral Philosopher.

${ }^{2}$ Conta-se que o velho Machado apreciava bastante os diálogos platônicos e figurava de Sócrates para a "nova geração", cercado e admirado por jovens escritores. Meses antes de falecer, em correspondência a Mário de Alencar, Machado afirma que se entretém com o Fédon de Platão e comenta: "veja como ando grego, meu amigo" (MACHADO DE ASSIS. Obra completa, v. 3, p. 1086). Ver também uma crônica no Bons Dias, 1 junho 1888, em que o autor compara sua sabedoria à de Sócrates.
} 
Sócrates introduz uma nova concepção de ironia na argumentação filosófica no intuito de se livrar dos paradoxos que ele mesmo lança contra os sofistas, e de confrontar à realidade as aparências. Vale notar que, no conto “Teoria do medalhão", escrito à época das Memórias, a ironia é definida como um "movimento ao canto da boca, cheio de mistérios, inventado por algum grego da decadência", provavelmente Sócrates, e "contraído por Luciano, transmitido a Swift e Voltaire, feição própria dos céticos e desabusados". ${ }^{3}$ Essa "transmissão" certamente chega até Machado. Isso nos faz crer que ele mesmo se considerava um ironista cético. Seja como for, pelo menos os narradores machadianos são ironistas por excelência. Eles tergiversam e se esquivam para que não tenhamos condições de lhes atribuir a verdade de suas afirmações, revisando constantemente seu vocabulário, o que nos força a um estado de cautela. Não se cria uma convenção de veracidade (pacto leitor-narrador), mas um ambiente de luta pela fixação do sentido em que um procura rebaixar o outro.

Os diálogos platônicos, assim como os romances machadianos, misturam ironias verbais e situacionais, combinam ficção e realidade, e descrevem a vivência e as discussões de alguns personagens. Os romances machadianos utilizam marcadores metareferenciais de modo que a própria forma se torna uma teoria de si mesma. A desenvoltura autorreflexiva do romance machadiano, segundo Roberto Schwarz,

(...) é um procedimento que supõe amplitude de vistas, capacidade analítica, fluência e concisão expositivas etc., sem prejuízo de estas aptidões estarem numa versão apalhaçada, o que estende a ação do abuso a territórios pouco batidos, à esfera das faculdades de conhecimento enquanto tais. ${ }^{4}$

"A obra em si mesma é tudo", nos diz Brás Cubas no intróito a suas memórias, inclusive como constituinte de sentido e fundamento do que se quer apresentar, ou seja, é a partir de si mesma que devemos construir uma teoria para interpretá-la. Devemos compreendê-la, de início, como "obra de finado", escrita "com a pena da galhofa e a tinta da melancolia”, que, em conjunto, resulta numa guinada irônica sobre si mesma. Brás vinga-se dos vivos (inclusive de si mesmo) escancarando suas contradições, e tenta fugir à Natureza vivenciando o que não se vive.

Assim como Brás Cubas, o "filósofo" de Platão utiliza-se da argumentação para se confrontar com a realidade; sua fala sugere a discrepância entre uma descrição de mundo e como o mundo é de fato. O que Sócrates diz significa algo de diferente e de contrário. A ironia surge de uma relação semântica problemática, quando a palavra e a coisa não mais correspondem; ao pensamento resta a criação de subterfúgios, isto é, esquemas conceituais que amenizam esta suposta contradição, e dentro dos quais se formulam estratégias comunicacionais para assimilar as contingências. Os interlocutores, por desconhecerem este estado volúvel de crença, se atordoam e vivenciam um estado de aporia.

A profissão de Sócrates é a ignorância. Como ensinar algo sem nada saber? Sócrates não é um sofista no sentido de cobrar para ensinar. Ele não expõe doutrinas à venda. $O$ que se oferece é um método de investigação "encarnado" no próprio Sócrates, ou seja,

\footnotetext{
${ }^{3}$ MACHADO DE ASSIS. Obra Completa, v. 2, p. 294.

${ }^{4}$ SCHWARZ. Um mestre na periferia do capitalismo: Machado de Assis, p. 26.
} 
seu modo de vida é um exemplo que deve e não deve ser seguido. Ao travar conhecimento com aqueles que se supõem mais versados, ao investigar os limites, a coerência, a forma ou o uso de determinado conceito, ele pretende, primeiramente, rebaixar seu interlocutor ao mesmo nível, a saber, de alguém que nada conhece. Sócrates faz com que reconheçamos a discrepância entre o suposto conhecimento de seus adversários e o que eles realmente sabem. Ao realizá-lo, ele se coloca num nível superior, pois é consciente de sua ignorância. O interlocutor acaba por se reconhecer nele. Apetece-se por Sócrates, como Alcebíades. Esse reconhecimento revela inferioridade. Sócrates é tomado como guia, dá a liberdade com uma mão, quando não sabe que caminho (positivo) indicar.

As ironias machadiana e socrática operam em suas estratégias argumentativas no sentido de nos tolher a atribuição de intenções e propósitos verdadeiros, garantindo o vigor das aporias. No famoso simpósio, Alcebíades afirma que Sócrates "leva a vida ironizando e debatendo com os homens", sempre nutrido de sua "habitual ironia", 5 que não é somente um tropo retórico cujo verdadeiro significado pode ser descoberto invertendo-se o que foi dito. Esta postura torna enamorados alguns que com ele se relacionam. Num primeiro momento, Alcebíades sente-se liberto e alentecido com o contato amoroso (de intercâmbio de ideias) de Sócrates. No momento seguinte, Alcebíades está sob seu poder: Sócrates não é o amante, mas o amado. Ele apenas sugere, nunca enuncia a ideia como tal, permanece sóbrio e distante. A esse respeito, Kierkegaard faz o interessante comentário: "o amor descrito é o da ironia, amor irônico, mas a ironia é o negativo no amor, é o incitamento do amor". ${ }^{6}$ Os elogios ao amor voltamse então para Sócrates, que responde:

Ah, querido Alcebíades, talvez não sejas realmente um homem tolo, se o que dizes de mim é verdade e existe em mim alguma qualidade que possa fazer-te um homem melhor. Neste caso verias em mim uma beleza indescritível e muito superior a tua bela figura. Por conseguinte, se a vês em mim e pretendes trocar comigo beleza por beleza, levarás sobre mim grande vantagem: tentas adquirir algo que é verdadeiramente belo em troco do que é aparentemente belo - "ouro por zinco".?

Percebe-se claramente que ironia, nesse contexto, não possui apenas os sentidos negativos usualmente atribuídos a Sócrates de engano, embuste e simulação. De que Alcebíades não é tolo seguem-se pelo menos três interpretações: (a) Que ele, de fato, não é tolo, pois mostra sagacidade e esperteza ao tentar trocar "ouro por zinco" (conhecimento por aparência); (b) Que ele, de fato, é tolo, porque pensa que Sócrates aceitará o trambique; (c) Que ele é e não é tolo, mesmo que não seja ao mesmo tempo e sobre o mesmo aspecto. Sócrates se mantém alheio ao enunciado atribuído (a), sugerindo tratar-se de algo inapropriado (b). Seu enunciado irônico marca a discrepância entre aquilo que sugere a descrição de mundo e como as coisas são de fato (c). $O$ propósito do ironista, embora predominantemente crítico, funciona enquanto solidariedade. Alcebíades obteria a "sabedoria" de Sócrates gratuitamente se não o

\footnotetext{
${ }^{5}$ PLATÃO. Banquete, 216e. Traduções nossas a partir de: PLATÃO. Obras completas.

${ }^{6}$ KIERKEGAARD. O conceito de ironia: constantemente referido a Sócrates, p. 53.

${ }^{7}$ PLATÃO. Banquete, 218d-219a. In: Obras completas.
} 
colocasse num pedestal, se não o seguisse como um guia, se não o amasse cegamente. Ele não foi enganado por Sócrates, mas por si mesmo. ${ }^{8}$

Os narradores machadianos, seguindo esta tendência, insistem na ideia de que seu leitor não os compreende, ora por avançar uma interpretação qualquer, ora por não supor o que para o autor é óbvio, ora recebendo deste um afago, ora um regateio. Por isso, muitos críticos consideram enganadores os narradores machadianos.

O "protagonista" de Machado tende a travestir de contradições a realidade, avaliando-a frente a posição histórica da Razão, percebida ao mesmo tempo como ultrapassada e inalcançada. A contradição é imposta aos caracteres das personagens, à matéria do enredo e à própria forma do romance. Ao generalizar o amor próprio e a busca desbaratinada por privilégios, Brás Cubas, segundo a leitura de Roberto Schwarz, estaria justificando a corrupção das elites brasileiras. Ao prever a derrota do homem frente ao inelutável, tingindo-a de melancolia, ele estaria desesperando qualquer transformação da estrutura social brasileira.

A leitura irônica de Schwarz tem a qualidade de se utilizar do mesmo procedimento irônico que o autor das Memórias, de modo que o próprio romance oferece uma teoria a partir da qual ele pode ser interpretado. Pretendemos mostrar que esta leitura, embora consistente, não consegue ler a filosofia do defunto autor senão como "desconversa ideológica", posto que todo enunciado seja lido em sentido inverso ao pretendido pelo narrador. Em nossa leitura, não há um verdadeiro sentido a ser descoberto por uma crítica perspicaz entre as linhas do narrador.

Ao se delinear, em alguns tipos, estratégias argumentativas à semelhança das de Sócrates, percebe-se que a equivocidade do dizer irônico, essencial para a compreensão da filosofia de Brás, inviabiliza a distinção entre sentidos patentes e ocultos, obrigando o interlocutor (ou leitor) a manter-se distanciado de sua própria interpretação, num gesto aporético que tende ao infinito. A consequência imediata desta concepção de ironia é garantir a autonomia da obra de arte. Em seguida, o falante (ou escritor) é condenado a um controle paranoico daquilo que diz. Segundo Patrick Pessoa, o problema é que,

(...) não contente com ser a um só tempo espectador de si mesmo (...) Brás Cubas entendeu que cumpria "evangelizar" os outros homens, transmitir-lhes (retoricamente) a sua filosofia do trágico, a um só tempo universalização de suas experiências particulares e condição para a sua memória póstuma como memória seletiva - o que, em seu passado, pudesse subverter a sua visão melancólica da existência, precisava ser necessariamente eliminado. ${ }^{9}$

Os ironistas de Machado utilizam-se de estratégia semelhante à socrática no que concerne à supremacia frente ao interlocutor, seja porque gostam da novidade, têm a capacidade de abandonar um modo prévio de ser e mudar de perspectiva, características que denotam a paranoia pelo controle da narrativa ou do diálogo.

Logo no primeiro capitulo, temos um narrador importuno fazendo poses ora de ingênuo, ora de entendedor, dizendo que seu óbito é coisa desimportante, mas comparando seu livro ao Pentateuco. Por fim, desafia o leitor:

\footnotetext{
${ }^{8}$ VLASTOS. Socrates: Ironist and Moral Philosopher, p. 78.

${ }^{9}$ PESSOA. A segunda vida de Brás Cubas, p. 238.
} 
Morri de uma pneumonia; mas se lhe disser que foi menos a pneumonia, do que uma idéia grandiosa e útil, a causa da minha morte, é possível que o leitor me não creia, e todavia é verdade. ${ }^{10}$

A ironia do narrador Brás Cubas nos provoca a refletir sobre esta verdade. Mas aí é tarde demais! Estamos presos em sua aporia. A pergunta levantada não é "como o cético pode viver o seu ceticismo", pois o autor empírico já está fora de cena, mas "como ele pode reproduzi-lo". Céticos de tipo aporético tendem a controlar o diálogo de modo a manter seu interlocutor em aporia. Os narradores-personagens de Machado manipulam, por exemplo, o status autoral. Brás Cubas seria um cético incapaz de viver seu ceticismo não fosse o fato de nos expor sua própria vida como parte do argumento aporético. Ora, como é possível ser defunto autor?

Por um lado, não se pode vivenciar este estado de fato, mas, a partir dele, pode-se rememorar algo que já não é. Por outro, o narrador manipula a condição de uma vivência autêntica, já que, pelo menos para a maioria dos homens, a "terrível opinião" é "obra superfina", ${ }^{11}$ solda das instituições domésticas e políticas. Além disso, desabrocha-lhe do peito uma opinião alheia à opinião pública e, portanto, mais veraz. À consciência desta experiência, Brás denomina "desdém dos finados", o que supostamente garante a seus enunciados a qualidade da franqueza. Logo, a autoria só seria possível se póstuma, pois apenas de uma posição neutra, sem o interesse e a vaidade, é que se pode descrever a vida (social e particular). A questão que se coloca é: por que devemos concordar com a neutralidade cética do relato póstumo quando percebemos um narrador tão mesquinho quanto seus personagens? O argumento de Brás é o seguinte:

O olhar da opinião, esse olhar agudo e judicial, perde a virtude, logo que pisamos o território da morte; não digo que ele se não estenda para cá, e nos não examine e julgue; mas a nós é que não se nos dá do exame nem do julgamento. Senhores vivos, não há nada tão incomensurável como o desdém dos finados. ${ }^{12}$

Ora, não é verdade que o autor permanece indiferente em relação ao que narra. Ele próprio o admite: "já se vai sentindo que o meu estilo não é tão lesto como nos primeiros dias (...) em cada fase da narração da minha vida, experimento a sensação correspondente". ${ }^{13}$ A seguir, veremos que a reação de Brás desautoriza a interpretação de que sua morte lhe trouxe a ataraxia, "ausência de padecimentos e perturbações próprios da experiência vital". ${ }^{14}$ Basta pensarmos em seu ressentimento contra Lobo Neves, "um homem que não era mais esbelto que eu, nem mais elegante, nem mais lido, nem mais simpático", ${ }^{15}$ "eu, que valia mais, muito mais do que ele", ${ }^{16}$ e em sua "vingança",

\footnotetext{
${ }^{10}$ MACHADO DE ASSIS. Obra completa, v. 1, p. 514.

${ }^{11}$ MACHADO DE ASSIS. Obra completa, v. 1, p. 612-613.

${ }^{12}$ MACHADO DE ASSIS. Obra completa, v. 1, p. 546.

${ }^{13}$ MACHADO DE ASSIS. Obra completa, v. 1, p. 627.

${ }^{14}$ MAIA NETO. O ceticismo na obra de Machado de Assis, p. 99

${ }^{15}$ MACHADO DE ASSIS. Obra completa, v. 1, p. 560.

${ }^{16}$ MACHADO DE ASSIS. Obra completa, v. 1, p. 564.
} 
já que Lobo Neves é descrito como um tolo. Perder Virgília e a candidatura é uma espécie de vitória para quem supostamente desacredita em compromissos eternos e joguetes políticos.

Outra questão é se Brás Cubas teria vencido a lógica implacável da Natureza. Um a um, altruísmo, poesia, ética, amor, política, filosofia, religião, toda ilusão que daria sentido a sua primeira vida passa pelo crivo da ironia de Cubas. Entre os capítulos L e CLIX, nada lhe escapa, assim como nada escapa à lógica da Natureza. Respectivamente, a filosofia da ponta do nariz, a sede de nomeada, a lei da equivalência das janelas, a solidariedade dos aborrecimentos, as teorias do momento oportuno e da vantagem, o Humanitismo, a teoria dos benefícios, todos são artifícios que mimetizam o modo de ser irônico da Realidade.

A estratégia argumentativa de Brás possui três facetas complementares: a antecipação irônica, a volubilidade e o argumento condicional.

Contra a Natureza implacável, que a tudo corrói, em primeiro lugar, a estratégia é universalizar sua filosofia trágica, antecipando a decadência e o fim de todas as coisas. Há morte antes da vida. A opinião se sobrepõe à verdade. Este mecanismo de antecipação irônica esconde a premissa de que nada vale a pena, mitigando a dor de um sofrimento específico e vindouro. Assim é o seu caso "amoroso" com Virgília. Todo amor, ou o amor em si, quando exemplificado e justificado por Brás Cubas, se transforma, aos olhos do leitor, em algo sem justificativa e valor. A verdade é que só um tolo como Lobo Neves poderia assumir o compromisso do amor, mesmo que não se trate do amor romântico.

Em segundo lugar, a volubilidade, artifício de desidentificação sistemática de si mesmo, configura a suposta desfaçatez e a impostura do narrador, forçando o leitor a um estado de sobreaviso, numa luta por supremacias - ideológica e semântica, em que a última palavra é do narrador. Nesse movimento instaurador de supremacias, de acordo com a leitura ideológica, a própria sociedade moderna se sujeita a volubilidade, a norma é vista como insurreição e a sequência narrativa se inverte.

De que vale a luta, se é imperativo aceitar as coisas como são? Ignorante, o homem não percebe que a Natureza ou o Capital são implacáveis. $O$ único modo de sobreviver é adequar-se ao sistema. Sem abstrair da inscrição social do pensamento brascubiano, nossa leitura compreende a melancolia, disposição afetiva conservadora sob um viés ideológico, num sentido existencial, como a dor da finitude. A fundação metafísica da melancolia, justificada e exemplificada, configura o critério filosófico de seleção dos eventos que entram na narrativa, desde que satisfaçam a forma humorística. Fazendo uma analogia, digamos que a forma da função é a "galhofa", e os valores que a satisfazem são os episódios que revelam a precariedade humana.

Ampliando ainda mais a perspectiva de Roberto Schwarz, o procedimento aporético encontra-se calcado na insuficiência do perspectivismo em relação aos materiais que o próprio autor representa, sobretudo no sentido filosófico. A mescla de crítica violenta e apologia, como em Montaigne e Sócrates, confunde vítima e algoz. O mecanismo satírico, ao nível dos caracteres, "está nas desculpas que inculpam, nas atenuantes que agravam, ou, mais genericamente, na função acusatória da defesa, conduzida com distanciamento de si mesma e em conivência com o leitor esclarecido". ${ }^{17}$

${ }^{17}$ SCHWARZ. Um mestre na periferia do capitalismo: Machado de Assis, p. 113. 
O cap. LXXIII, por exemplo, tem o seguinte esquema: a) defesa de Cotrim, apresentando a normalidade de sua conduta pelo ângulo econômico; b) acusação de Cotrim, apresentando o escravismo como uma infração aos direitos do Homem pelo ângulo liberal; c) denúncia da defesa, demonstrando a fragilidade dos argumentos, pois se julga uma experiência histórica segundo o critério da outra (heterogênica e indisputável). Do ponto de vista ideológico, a questão é como qualificar a contradição do perfil, cuja fissura interna separa o paradigma do progresso europeu e a classe dominante brasileira? Sob o viés da filosofia de Brás Cubas, a questão se coloca sobre a contradição ínsita aos caracteres, submetendo os eventos a uma espécie de antropologia irônica. Ao sentenciar que nada escapa ao "enxurro da vida", Brás busca, através do exercício da galhofa, provar a verdade objetiva de sua melancolia: "Marcela, Sabina, Virgília... aí estou eu a fundir todos os contrastes, como se esses nomes e pessoas não fossem mais do que modos de ser da minha feição interior." 18

No âmbito do enredo, a estratégia da volubilidade também estabelece contradições e aporias. A atitude filosófica está na enunciação de generalidades sobre o humano em forma sentenciosa ou apologal, cujos tópicos são a constância da inconstância e a universalidade do egocentrismo. Ao desconsiderar a amplitude filosófica de Brás Cubas, Schwarz tem de admitir que o ambiente problemático-apalhaçado do livro se compõe de horizontes incompatíveis e ecléticos. Contudo, se pensamos que a descrição da morte do personagem coincide com a descrição do nascimento do narrador, então a melancolia, que se anuncia desde a morte da mãe de Brás e se consolida com o delírio, nos indica o fio que conduz à própria gênese da filosofia do narrador. Nesse período trágico, o personagem Brás se "retira" da vida e encontra na "volúpia do aborrecimento" a única resposta existencial satisfatória contra a implacável Natureza. Se ela nos força a atuar, Brás, consciente de sua condição, nada faz, experimentando uma espécie de morte e antecipando, trágica e ironicamente, seu próprio destino.

O recurso à antecipação irônica se mantém na forma do romance, cujo padrão argumentativo é o seguinte: (a) Toma-se um episódio em veia realista. Mostra-se a contradição do homem que se quer moderno; (b) Intercala-se um episódio cujo movimento interrompe o anterior, seja por um gesto narrativo de soberania, seja pela busca de reconhecimento; (c) Noutro nível, a forma filosófica e universalista da narrativa rebaixa a condição realista a detalhe marginal; (d) Estabiliza-se o primado da aporia e a investigação não se conclui. Toma-se outro episódio em veia realista, sublinhando o caráter arbitrário da intercalação... A própria volubilidade é volúvel: designa a condição humana, a feição do narrador ou as características da sociedade brasileira.

Com a repetição do ciclo, a relação essencial (a) e inessencial (b) se inverte de modo que este passe a formar a ambiência filosofante daquele. Logo, a forma das Memórias é delineada pela sutileza do narrador, que se expressa imediatamente como a estratégia filosófica de tergiversar e escapar da acusação, comum contra os céticos, da autorrefutação. Memórias póstumas de Brás Cubas é um livro escrito contra seu pseudoautor do ponto de vista ideológico, mas não filosófico. A redução ideológica operada por Schwarz converte as questões filosóficas em meros filosofemas, cuja função exclusiva é desmascarar o

${ }^{18}$ MACHADO DE ASSIS. Obra completa, v. 1, p. 564. 
interesse classista por detrás de uma metafísica eclética e insossa. Em nossa interpretação, ao contrário do que pensa Schwarz, o ceticismo demanda a volubilidade, isto é, a argumentação evasiva e instauradora de aporias.

O ciclo descrito por Patrick Pessoa nos mostra de modo mais claro a gênese filosófica do narrador: melancolia $=>$ inação $=>$ distanciamento irônico $=>$ surgimento do narrador $=>$ percepção da homogeneidade do tempo $=>$ visão da irônica tragicidade da própria Natureza $=>$ ressentimento com relação a uma Natureza que não é o que deveria ser $=>$ melancolia $=>$ inação (reação) $\ldots$

A ênfase, que de início recai sobre a inação do Brás Cubas, na segunda volta recai sobre sua reação contra a Natureza (que, para o espanto de Brás, é mãe e inimiga), de modo que a ironia passa a ser a principal arma retórica para provar a verdade de sua melancolia. Portanto, a inação ou a reação de Brás Cubas de modo algum equivalem à ataraxia.

A última faceta da estratégia argumentativa de Brás Cubas é o argumento condicional. A ironia utilizada frente à filosofia de Quincas e, generalizando, a uma redenção pela filosofia, é de tipo socrático.

Em vez de ele próprio filosofar sobre o que há de impossível, risível e hipócrita na filosofia, como fizera no caso do amor, agora Brás Cubas dissimuladamente se fará passar pelo principal discípulo de Quincas Borba, para, ao lhe dar voz, uma voz assaz caricatural, expor de forma ainda mais contundente o ridículo das pretensões hermenêuticas da filosofia e, assim, garantir a verdade de sua filosofia do trágico, de sua melancolia. ${ }^{19}$

A filosofia de Borba é o exato oposto da filosofia melancólica de Cubas. Ao incorporar em sua narrativa os argumentos do Humanitismo, Brás antecipa-se a possíveis objeções a sua própria filosofia. Ao contrário do que sugere o defunto autor, segundo Quincas, absolutamente tudo tem um fim determinado, tal é a lei de Humanitas, que, seguida a risca, faz da dor uma ilusão, e o pensamento de Brás se torna uma filosofia "do choramingas". No intuito de negar a negação da objetividade de sua melancolia e, por conseguinte, afirmar a verdade de sua filosofia, Brás Cubas se passa por discípulo de Quincas Borba. À maneira de Sócrates, o argumento condicional é o seguinte: se meu oponente está correto, então eu devo me tornar seu discípulo. Contudo, ao viver segundo os mandamentos do Humanitismo, descubro contradições insuperáveis. Logo, o oposto desta filosofia deve ser verdadeiro.

Sócrates também molda com ironia o método de que dispõe, o élenchos, que verifica verdades morais conforme as respostas do interlocutor. Uma tese é debatida se asseverada como a própria crença do contendor e é contestada totalmente no caso de sua negação ser deduzida das crenças. Vlastos assim o caracteriza: (1) Sócrates extrai uma resposta "A" para uma questão colocada a um interlocutor; (2) Sócrates faz seu interlocutor admitir que certos juízos, embora logicamente independentes, acarretam a falsidade de "A"; (3) ambos (quase sempre) concordam que isso mostra (ou até mesmo prova) que "A" é falsa. (4) Enfim, Sócrates alega que, se "A" é falso, A é verdadeiro.

${ }^{19}$ PESSOA. A segunda vida de Brás Cubas, p. 212. 
A questão que se coloca é: por que alguém deve concordar que "A" é falsa (e não outra crença), se se mostra apenas a inconsistência de "A" com as admissões subsequentes do interlocutor? Sócrates denuncia a confusão e o equívoco das perspectivas alheias. As verdades morais que ele reconhece estão sempre entre as premissas e nunca entre as conclusões do argumento elêntico. Vale lembrar que este método não se aplica a si mesmo e que Sócrates manipula sorrateira e paranoicamente as regras do debate. ${ }^{20}$

De um ponto de vista lógico, este sofisma mostra apenas a inconsistência de um conjunto de proposições, conquanto demonstre na prática que o interlocutor diz coisas que não podem ser verdadeiras em conjunto. Contudo, este método não oferece critérios para indicar qual crença deve ser abandonada. Regressa-se, por conseguinte, à proposição inicial. Sócrates mantém o interlocutor nessa aporia. O problema é como Sócrates poderia dissimular e dizer coisas que não acredita quando sua primeira regra é "dizer o que se acredita"?

No Górgias, Sócrates diz que "não fala como alguém que sabe". Referindo-se à justiça e injustiça, alega "não saber como essas coisas são", e repetidas vezes que "esse é seu modo de falar". ${ }^{21}$ Ele se espanta com o relato do Oráculo de Delfos, segundo o qual não haveria alguém mais sábio que Sócrates (Apologia 21b). O paradoxo torna-se ainda mais complexo se pensamos, como Sócrates, que conhecimento e sabedoria são virtudes. Como ele seria virtuoso ou feliz sem conhecimento?

Sócrates é sincero ao advogar a "supremacia da virtude", tese segundo a qual a melhor vida é a virtuosa, sem se definir virtude. ${ }^{22}$ Vale a mesma lógica do argumento condicional de Brás Cubas frente a filosofia de Quincas Borba: se o antecedente (a resposta do interlocutor) é verdadeiro, então Sócrates deve crer no consequente (que seu interlocutor conhece algo). Contudo, temos boas razões para crer que Sócrates desacredita o antecedente e o consequente, ao mesmo tempo que mantém a condicional como um todo. Portanto, nunca o que ele fala contradiz estritamente sua crença.

Eutífron, por exemplo, oferece uma descrição precisa de piedade e Sócrates imediatamente se declara seu seguidor. O filósofo de Platão faz o seguinte raciocínio condicional: se Eutífron de fato sabe o que é piedade, então eu devo me tornar seu pupilo. Acontece que Sócrates desconfia que Eutífron não possua conhecimento. A ironia condicional é um tropo ad hominem, uma vez que parte de uma crença básica do interlocutor, a saber, que ele possui algum conhecimento. ${ }^{23}$

Sócrates aceita a "supremacia da virtude", e tenta persuadir os outros a viverem de acordo com ela. Quando ele diz que não está se defendendo propriamente, mas ao júri, ele já é alguém que agiu de acordo com a ironia condicional por toda a vida, e

\footnotetext{
${ }^{20}$ VLASTOS. The Socratic elenchus, p. 712. Segundo Vlastos, não ocorre a autorreferencialidade porque o método não é, ele mesmo, uma questão moral. Por razões semelhantes não se investiga as condições lógicas para uma resposta correta à questão "O que é F?".

${ }^{21}$ PLATÃO. Górgias, 506a-509a. In: Obras completas.

22 PLATÃO. Apologia, 29b. In: Obras completas.

${ }^{23}$ Cf. PLATÃO, Eutífron 4e2-5a2. In: Obras completas. Sobre a ironia condicional, ver VASILIOU. Conditional Irony in the Socratic Dialogues, p. 456-472. O argumento flui bem se não o consideramos como um caso de sarcasmo. Nós, os leitores, conhecemos Sócrates e sabemos que eles se conhecem. No caso de Brás Cubas, não temos como atestar sua sinceridade. A nosso ver, isto caracteriza uma das principais aporias de que Brás lança mão.
} 
agora sabe que sua fala será diretamente compreendida como irônica, embora ele esteja sendo sincero - e nós sabemos disso porque conhecemos a "supremacia da virtude" que ele advoga. Ocorre uma discrepância nas crenças e ações de Sócrates em comparação às crenças e ações do júri. A audiência torna-se incrédula, desconfia que Sócrates escarninha e brinca, tornando-os perplexos mesmo antes de se mostrar qualquer inconsistência em suas crenças. Uma vez comprometido com a "supremacia", devemos considerar suas declarações (de que cometer injustiça é pior que sofrê-la, por exemplo) sinceras. Ao tornarem-se perplexos em relação a suspeita de insinceridade e não em relação à inconsistência de suas crenças, Cálicles e Pólo experimentam a aporia.

Colocando-se do ponto de vista daquele que enuncia um paradoxo tão mais abrangente que seu enunciado, mas escapando à autocontradição, como Sócrates e Brás Cubas, o ironista realiza em si sua ironia. Além disso, eles parecem seguir a intuição de que, para enunciar uma verdade, não basta cortar a própria carne e servir de exemplo para a verdade que professa. É preciso universalizá-la, vê-la repetir-se monotonamente.

Sócrates não sabe o que é ou o que há após a morte, e sua ignorância o liberta. Por isso, sente-se no direito de descrevê-la através de mitos. Morto, Brás se diz indiferente em relação aos vivos, liberto da vida. Por isso a esmiúça. Quase morto, com o corpo rijo e frio, Sócrates ainda lembra Críton de pagar um galo a Asclépio. Brás Cubas é ainda mais espirituoso e dedica suas Memórias póstumas "ao verme que primeiro roeu as frias carnes” de seu cadáver. O estilo de Machado em Memórias póstumas de Brás Cubas permite a realização da ironia existencial, mais próxima da concepção kierkegaardiana do que de um liberalismo rortyano.

Vimos que as estratégias argumentativas de Sócrates e Machado de Assis têm em comum a tendência de rebaixar seu interlocutor e exigir o reconhecimento de alguma supremacia. Brás Cubas ridiculariza seu interlocutor e, indiretamente, a classe social a que ele pertence, de modo que o ceticismo aporético se expressa através da volubilidade. No âmbito filosófico, Brás Cubas, em sua vida original de autor, preocupa-se com verdades morais, à maneira de Sócrates, Montaigne e Pascal, formulando miniteorias antropológicas que explicam a vida social. Do ponto de vista prático, ele simplesmente se torna um cético que não pode viver plenamente seu ceticismo.

A despeito de não possuir conhecimento, o interlocutor de Sócrates crê que sabe algo, e isto o torna ainda mais ignorante. ${ }^{24} \mathrm{~A}$ falácia de Sócrates está em manipular os critérios do justo debate. Para ele vale a medida da ironia condicional: se o interlocutor soubesse algo, então... Para o interlocutor, o peso recai sobre suas próprias crenças, não lhe cabendo o direito ao mesmo argumento condicional.

Se nossa interpretação da função do Humanitismo nas Memórias está correta, ou seja, se se trata mesmo de um argumento condicional que visa afirmar a filosofia brascubiana, não restam dúvidas quanto a originalidade formal deste pensamento. Literatura e ceticismo se combinam de maneira magistral. Certamente quanto à desenvoltura filosófica deste memorialista, que sequer deixa para a humanidade o emplastro que cura (se é que ele o inventou): "e aí vos ficais eternamente hipocondríacos". Não ter nascido, ou não ter filhos, ao contrário do que prega Humanitas, para quem desgraça é "não

${ }^{24}$ PLATÃO. Apologia, 21d2-6. In: Obras completas. 
nascer", eis o saldo destas memórias. Esta filosofia trágica tende ao niilismo pirrônico, caso não acrescentemos o tom galhofeiro com que o autor tinge sua obra. Devemos levá-lo mesmo a sério? A sinceridade, pretensamente uma exigência do gênero autobiográfico, torna Brás Cubas um dogmático no que diz respeito a uma perspectiva ética da vida, como pensa Maia Neto?

Em Machado e Sócrates, está apurada a qualidade irrealizável da virtude, seja porque não se alcança uma definição correta (no caso de Sócrates), seja porque toda ação virtuosa é maculada (como demonstram as miniteorias de Brás). Ficamos em aporia porque não temos condições de atribuir os verdadeiros propósitos a Sócrates e nem a Brás Cubas. Fôssemos menos ingênuos, não concordaríamos com a neutralidade do defunto autor em esmiuçar a matéria humana; tampouco abandonaríamos nossas crenças básicas quando Sócrates mostra apenas a inconsistência de certo conjunto de crenças. O método machadiano tem a vantagem de colocar a questão sobre si mesmo. Como mostramos, a forma composicional faz parte de seu argumento aporético. O status literário permite a Machado de Assis defender uma posição original, que responde a questões abertas pelo ceticismo moderno. Se Sócrates, que nos ensinou o método aporético, é considerado um grande pensador, apesar de seus sofismas, por que ainda hesitamos em reconhecer o filósofo de Machado de Assis?

\section{A4}

\section{A B S TRACT}

Our aim is to compare some general argumentative strategies of Socrates and Brás Cubas, such as irony and aporia. We consider fictional structure as a condition for the skeptical expression, which, when we distrust reality or whatever we assume to know about it, restore a new perspective over that reality, that is, another level of reality which leaves out dogmatic values like Truth and Essence. The general justification for this kind of approach is that the questions there illustrated are embodied by fictional situations, generating a skepticism expressed in fictional work. Machado's philosopher sketches conjectures that describe human beings' paradoxical relations.

\section{KEYWORDS}

Machado de Assis, Socrates, Skepticism

\section{REFERÊNCIAS}

KIERKEGAARD, S. O conceito de ironia: constantemente referido a Sócrates. 2. ed. Rio de Janeiro: Vozes, 2005. 283 p.

MAIA NETO, J. R. O ceticismo na obra de Machado de Assis. São Paulo: Annablume, 2007. 197 p.

MACHADO DE ASSIS, J. M. Obra completa. Rio de Janeiro: Nova Aguilar, 2006. 3 v. 3.612 p. 
PESSOA, P. A segunda vida de Brás Cubas. Rio de Janeiro: Rocco, 2008. 286 p.

PLATÃO. Obras completas. Tradução do grego, preâmbulo e notas por Maria Araujo [et al.]. 2. ed. Madrid: Aguilar, 1972. 1.715 p.

SCHWARZ, R. Um mestre na periferia do capitalismo: Machado de Assis. 2. ed. São Paulo: Duas Cidades, 1991. 227 p.

VASILIOU, I. Conditional Irony in the Socratic Dialogues, The Classical Quarterly (New Series), Cambridge, v. 49, n. 2, p. 456-472, Dec. 1999.

VLASTOS, G. Socrates: Ironist and Moral Philosopher. Ithaca; New York: Cornell University, 1991. $334 \mathrm{p}$.

VLASTOS, G. The Socratic elenchus. The Journal of Philosophy, New York, v. 79, n. 11, Seventy-Ninth Annual Meeting of the American Philosophical Association, Eastern Division, p. 711-714, Nov. 1982. 